\title{
Interrupted right aortic arch in DiGeorge syndrome
}

\author{
P MOERMAN, * M DUMOULIN, $\dagger$ J LAUWERYNS, * \\ L G VAN DER HAUWAERT $\dagger$
}

From the $\star$ Department of Pathology I and the $\uparrow$ Section of Paediatric Cardiology, Gasthuisberg University Hospital, Leuven, Belgium

SUMMARY The clinical and necropsy findings in four cases of interrupted right aortic arch and right descending aorta associated with DiGeorge syndrome (congenital absence or hypoplasia of $\nexists$ the thymus and parathyroids) are described. All patients had a mirror image of type $B$ interruption, namely a right aortic arch with reversed branching pattern and an interruption between the right common carotid and right subclavian artery. In two patients there was a doubly committed subarterial ventricular septal defect and in the two other patients there was a perimembranous septal defect. Three patients had a bicuspid aortic valve. In a consecutive series of 185 necropsies in infants and children with congenital heart disease there were no cases of interrupted right aortic arch that were not associated with DiGeorge syndrome.

These observations and previous reports indicate that the concurrence of these two rare conditions is more than fortuitous. In patients with an interrupted aortic arch the clinician should be aware of the common association with DiGeorge syndrome. If the interruption is associated with a right-sided descending aorta it is highly probable that the patient has DiGeorge syndrome.

Interruption of the aortic arch is an uncommon cardiovascular anomaly which is almost invariably associated with a left-sided descending aorta, continuous with a left ductus arteriosus. ${ }^{1-3}$ There are only a few recorded cases of interruption associated with a right-sided aortic arch. ${ }^{3-6}$ We found this anatomical arrangement in four patients seen during the past ten years. In all four patients the thymus was absent, hypoplastic, or ectopic, as is characteristically seen in DiGeorge syndrome. ${ }^{7}$ The concurrence of these two rare conditions is more than fortuitous and is therefore reported.

\section{Patients and methods}

Nineteen cases with absence or hypoplasia of the thymus were found in a consecutive series (June 1976 to October 1986) of 185 necropsies in infants and children with congenital heart disease. All patients had major cardiovascular malformations (table

Requests for reprints to Dr P Moerman, Department of Pathology I, Gasthuisberg University Hospital, 3000 Leuven, Belgium.

Accepted for publication 29 April 1987
1). Twelve patients had an interrupted aortic arch, which was left-sided in eight cases and right-sided in four cases. This paper deals with the findings in the four patients with an interrupted aortic arch and a right-sided descending aorta, two of whom (cases 1 and 2) were mentioned in a previous report. ${ }^{5}$ Apart from these four patients no other cases of interrupted right aortic arch could be traced from our necropsy or clinical files.

Agenesis and hypoplasia of the thymus were defined as total or partial developmental absence of the gland respectively. Stress involution was distinguished from hypoplasia because it caused sym-

Table 1 Major cardiovascular malformations in 19 patients with DiGeorge syndrome

\begin{tabular}{|c|c|}
\hline Malformation & No \\
\hline $\begin{array}{l}\text { Interrupted aortic arch: } \\
\text { Left aortic arch } \\
\text { Right aortic arch }\end{array}$ & $\begin{array}{l}8 \\
4\end{array}$ \\
\hline $\begin{array}{l}\text { Truncus arteriosus: } \\
\text { Left aortic arch } \\
\text { Right aortic arch }\end{array}$ & $\begin{array}{l}3 \\
2\end{array}$ \\
\hline $\begin{array}{l}\text { Tetralogy of Fallot: } \\
\text { Right aortic arch } \\
\text { Total }\end{array}$ & $\begin{array}{r}2 \\
19\end{array}$ \\
\hline
\end{tabular}


metrical shrinkage and the persistence of the normal bilobed anatomy. In three of the four patients the tissue of the anterosuperior mediastinum and cervical region, which had been removed en bloc, was serially sectioned at $5 \mu \mathrm{m}$, and every tenth section was stained and histologically examined. By analogy with the classification proposed by Celoria and Patton ${ }^{1}$ we used the term "type B interruption" of the aortic arch when the interruption was situated between the right common carotid artery and the right subclavian artery. Ventricular septal defects were classified according to Becker and Anderson. ${ }^{8}$

\section{Results}

CLINICAL DATA

All four patients were admitted in the first weeks of life with severe and intractable congestive heart failure. They died at $2,12,16$, and 17 days of age. The concentration of serum calcium was normal in the two patients (cases 2 and 3 ) in whom it was measured. Craniofacial stigmata characterised by low-set

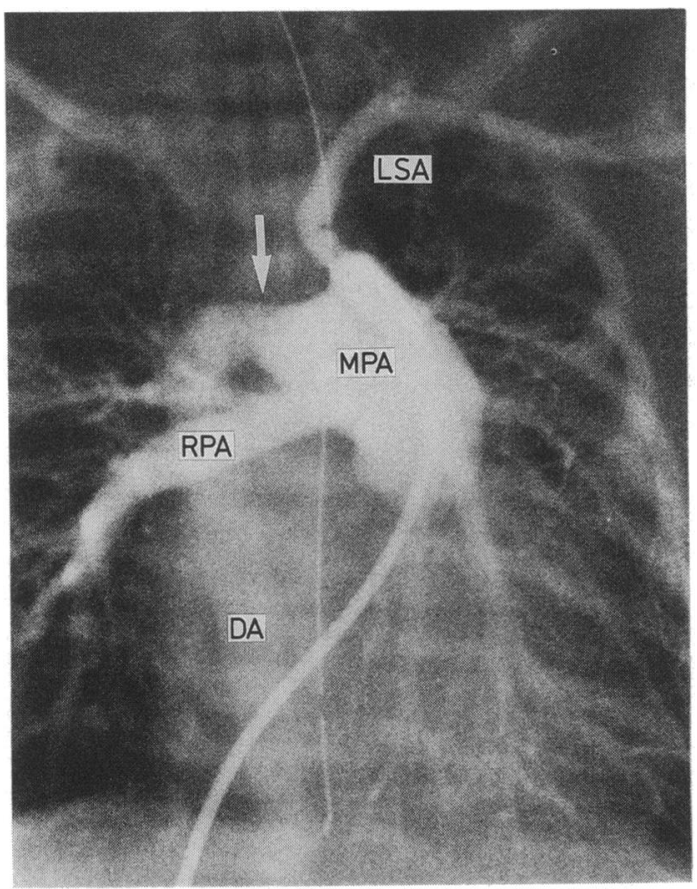

Fig 1 Angiogram in case 2 showing filling of the pulmonary artery and a bilateral ductus arteriosus. $A$ right-sided descending aorta communicated with the pulmonary artery through a large right ductus arteriosus (white arrow). The left subclavian artery filled through a left ductus arteriosus. $D A$, descending aorta; $L S A$, left subclavian artery; $M P A$, main pulmonary artery; $R P A$, right pulmonary artery. ears, ocular hypertelorism, retrognathia, and a fish-mouth appearance were seen in cases 3 and 4 .

Cardiac catheterisation and angiocardiography were performed in three patients (cases 1,2 , and 4). Considerable pulmonary hypertension, equal pressures in the right and left ventricles, and a large left-to-right shunt at the ventricular level were demonstrated. The systolic pressure in the right-sided descending aorta, which in all three patients could easily be entered from the pulmonary artery via a right-sided ductus arteriosus, was slightly lower than in the ventricles. The angiograms showed the characteristic features of interruption of the aortic arch, which will be discussed in more detail (fig 1).

\section{CARDIOVASCULAR ANOMALIES}

Table 2 shows the major cardiovascular findings at necropsy. In each of the four cases the interruption of the aortic arch was type $B$. The descending aorta was located to the right of the oesophagus and was supplied by a right ductus arteriosus arising from the pulmonary trunk. The right subclavian artery arose from the superior aspect of the descending aorta. In cases 1,3 , and 4 the first branch of the ascending aorta was the left innominate artery, which gave rise to the left subclavian and the left common carotid artery; the right common carotid artery was the second branch (fig 2). In case 2 the ascending aorta gave rise only to the left and right common carotid arteries (fig 3). In this exceptional case a bilateral ductus arteriosus was identified. The left subclavian artery was isolated from the aortic arch and connected with the pulmonary trunk via a left ductus arteriosus. The right ductus arteriosus supplied the descending aorta.

In cases 1 and 2 a doubly committed subarterial ventricular septal defect was found. This defect was located directly beneath the aortic and pulmonary valves and its floor was formed by the fused portions of the trabecula septomarginalis and the ventriculoinfundibular fold (fig 4). In the remaining two patients with perimembranous ventricular septal defect the infundibulum was slightly deviated to the left, causing some muscular subaortic stenosis. Patients 1, 2, and 4 had a bicuspid aortic valve.

\section{THYMUS AND PARATHYROIDS}

In two patients (cases 3 and 4) rudimentary fragments of the thymus could be identified macroscopically. Serial histological examination of the cervical and mediastinal tissue showed small thymic remnants in the remaining two patients. The histological structure of this thymic tissue was normal. Evidence of involution was slight to moderate. After serial sectioning and histological examination of the anterior mediastinum and neck, two normal para- 
Table 2 Pathological findings

\begin{tabular}{|c|c|c|c|c|c|c|c|}
\hline $\begin{array}{l}\text { Patient } \\
\text { No }\end{array}$ & Sex & $\begin{array}{l}\text { Age'at } \\
\text { de'ath }\end{array}$ & Thymus & Purathyroids & $\begin{array}{l}\text { Type of } A o A \\
\text { interruption }\end{array}$ & $I S I)$ & $\begin{array}{l}\text { ()ther cardiovascular: } \\
\text { anomalies }\end{array}$ \\
\hline 1 & F & 12 days & $\begin{array}{l}\text { Absent. } \\
\text { Small nodule ( } 7 \mathrm{~mm} \text { ) in } \\
\mathrm{R} \text { upper mediastinum }\end{array}$ & Not examined & B & $\begin{array}{l}\text { Doubly committed } \\
\text { subarterial }\end{array}$ & Bicuspid AoV \\
\hline 2 & F & 16 days & $\begin{array}{l}\text { Absent. } \\
\text { Yiny nodulc along } \mathrm{R} \\
\text { carotid }(0.4 \mathrm{~g})\end{array}$ & $\begin{array}{l}2 \text { normal } R \text { glands. } \\
\text { L. gland absent }\end{array}$ & B & $\begin{array}{l}\text { Doubly committed } \\
\text { subarterial }\end{array}$ & $\begin{array}{l}\text { Bicuspid AoV. } \\
\text { Bilateral PDA. } \\
\text { L subclavian arteng } \\
\text { connecting with } \\
\text { PDA }\end{array}$ \\
\hline 3 & $\mathrm{~F}$ & 2 days & $\begin{array}{l}\text { Absent I. lobe. } \\
\text { Small R lobe }(2.7 \mathrm{~g}) \\
\text { in R upper mediastinum }\end{array}$ & $\begin{array}{l}2 \text { hypoplastic } \\
\text { glands }\end{array}$ & B & $\begin{array}{l}\text { Perimembranous } \\
\text { infundibular }\end{array}$ & None \\
\hline 4 & F & 17 days & $\begin{array}{l}\text { Absent R lobe. } \\
\text { Small I lobe }(1.6 \mathrm{~g}) \\
\text { in } \mathrm{L} \text { upper mediastinum }\end{array}$ & Absent & B & $\begin{array}{l}\text { Perimembranous } \\
\text { infundibular }\end{array}$ & $\begin{array}{l}\text { Bicuspid AoV. } \\
\text { I. shift of CSV apd } \\
\text { subaortic } \\
\text { encroachment }\end{array}$ \\
\hline
\end{tabular}

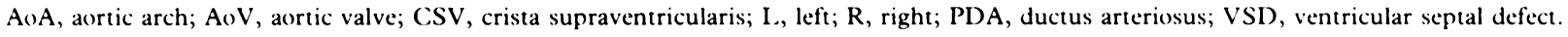

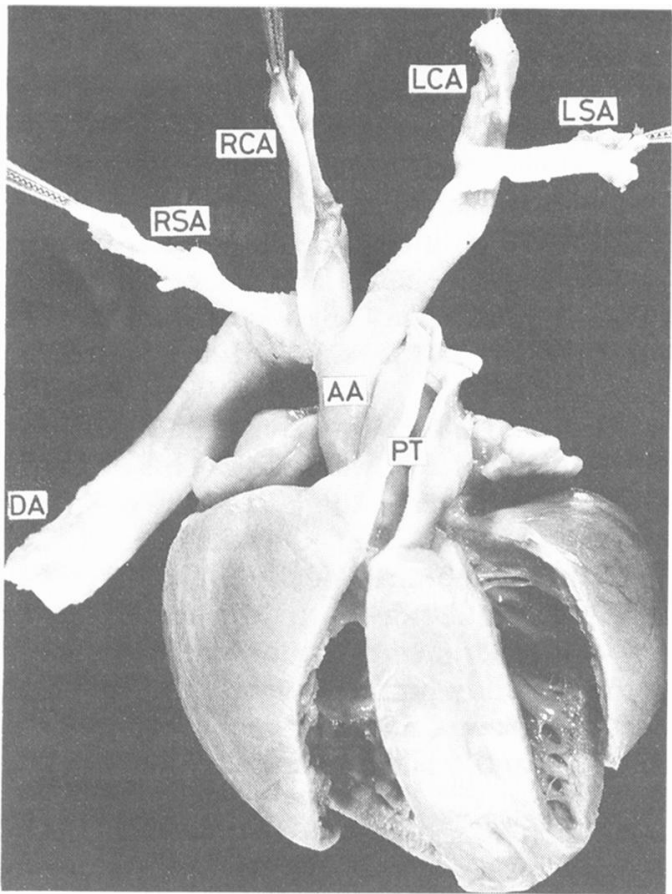

Fig 2 Photograph showing interrupted right aortic arch type $B$ in case 3. The right-sided descending aorta communicated with the pulmonary artery through a wide right ductus arteriosus. $A A$, ascending aorta, $D A$, descending aorta, $L C A$, left common carotid artery, L.SA, left subclazian artery; $R C A$, right common carotid artery; RSA, right subclavian artery; $P T$, pulmonary trunk.

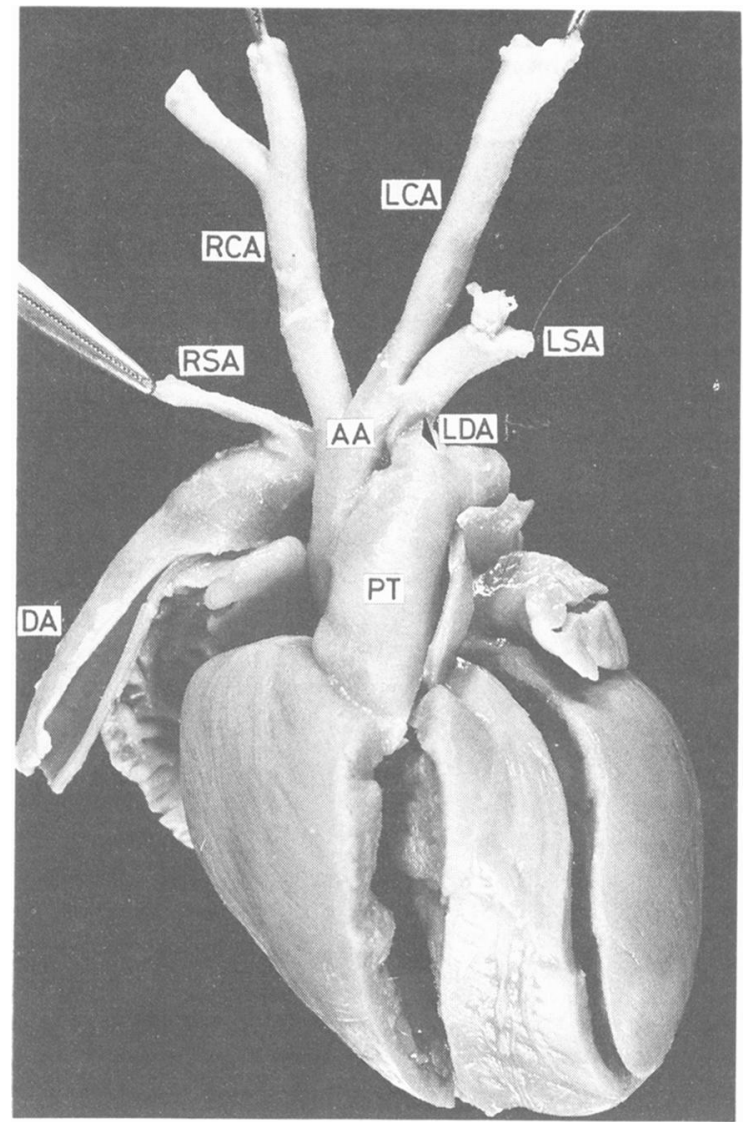

Fig 3 Photograph showing interrupted right aortic arch type $B$ in case 2. A bilateral ductus arteriosus was identified. The left subclavian artery was isolated from the aortic arch and connected to the pulmonary trunk via a left ductus arteriosus (IDDA). The right ductus arteriosus supplied the descending aorta. Se' fig 2 for abbreviations. 


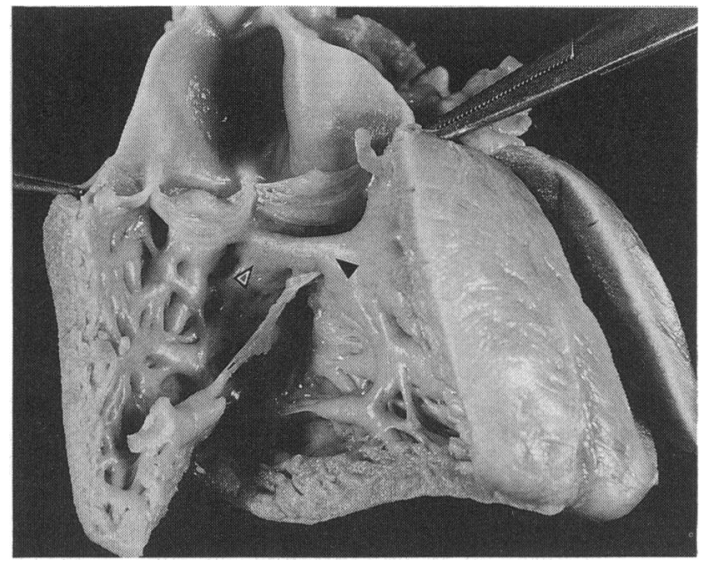

Fig 4 Photograph showing doubly committed subarterial ventricular septal defect in case 1 . In the opened right ventricle the defect was seen directly beneath the pulmonary valve. Its floor was formed by the fused portions of the trabecula septomarginalis (closed arrow) and the ventriculoinfundibular fold (open arrow).

thyroid glands were detected in case 2, two hypoplastic glands in case 3, and no parathyroids in case 4. When present, the glandular tissue showed a normal histological structure.

\section{Discussion}

DiGeorge syndrome is a complex of malformations of unknown aetiology that is generally attributed to failure of the development of derivatives of the third and fourth pharyngeal pouches. The essential features are congenital absence or hypoplasia of the thymus and parathyroid glands. The extent of the underdevelopment of these organs and the corresponding variation in the degrees of deficient cellular immunity and hypocalcaemia led to a classification in which partial and complete forms of the syndrome are distinguished. ${ }^{7}$ Facial stigmata, characterised by ocular hypertelorism, narrow palpebral fissures, a fish-mouth appearance, micrognathia, and deformed ear lobes are seen in more than half the cases. ${ }^{59}$ Severe cardiovascular malformations are found in nearly all patients with either the complete or partial form of the syndrome. ${ }^{59-11}$ The vast majority of these malformations may be classified as aortic arch anomalies (right aortic arch, interrupted aortic arch, aberrant origin of the subclavian arteries) or conotruncal anomalies (truncus arteriosus, tetralogy).

DiGeorge syndrome is not as rare as generally thought. The fact that we found 19 patients with complete or partial absence of the thymus in a series of 185 infants and children with congenital heart disease who came to necropsy within a 10 year period may be due to the interest that the pathologists were taking in this syndrome and the attention they paid to the development of the thymus and parathyroid glands. Twelve of these 19 cases had interruption of the aortic arch, which was associated with a rightsided descending aorta and a right patent ductus arteriosus in four patients (table 1). No other cases of interrupted right aortic arch were encountered in this necropsy series nor in a patient population of approximately 5000 infants and children with congenital heart disease investigated during the same period. Thus we have not come across a single case of interrupted right aortic arch not associated with DiGeorge syndrome. Three additional patients in the necropsy series had a right-sided aortic arch and descending aorta, which was associated with truncus arteriosus in two and tetralogy of Fallot in one case. A high frequency of right aortic arch in DiGeorge syndrome (seven out of 19 cases in the present series) has also been noted by others: it was found in $42 \%$ of 52 cases compiled by Moerman et $\mathrm{al}^{5}$ and in $24 \%$ of a series of 50 patients reported by Van Mierop and Kutsche. ${ }^{11}$

In view of the high frequency of right aortic arch and the equally high frequency of interrupted aortic arch in DiGeorge syndrome, it is not surprising that all three malformations were found in some patients. To our knowledge eight cases of interrupted right aortic arch have been reported. Pierpont et al described the pathological features in four cases but did not mention the anatomy of the thymus. ${ }^{6}$ Nor was it mentioned in two other cases. ${ }^{24}$ So we can only speculate about the presence of thymic aplasia or hypoplasia in these patients. In the remaining two patients, ${ }^{11} 12$ however, and in the four patients in our series in whom the thymus was examined, the typical features of DiGeorge syndrome were found. Interruption of the aortic arch with right descending aorta may cause compression of the right main bronchus, resulting in severe lobar emphysema of the right lung. ${ }^{6}$ This complication was not encountered in our patients.

Our observations support the concept that the basic developmental defect in DiGeorge syndrome affects the cephalic neural crest. Experimental studies have shown that normal aorticopulmonary septation and thymic morphogenesis depend on derivatives of the cephalic neural crest. ${ }^{13-15}$ In early embryogenesis, mesenchymal cells from the neural crest also contribute to the connective tissue, bone, and cartilage of the face and branchial arches. ${ }^{16}$ In DiGeorge syndrome an abnormal neural crest and abnormal migration of branchial arch mesenchymal tissue probably result in an abnormal facies, partial or complete absence of the derivatives of the third 
and fourth pharyngeal pouches (thymus and parathyroid glands), and conotruncal cardiac defects. The aortic arch anomalies that are found in many of these patients might be secondary to conotruncal maldevelopment causing reduced anterograde blood flow in the ascending aorta and impeded normal growth of the aorta. ${ }^{17}$ Recently, Lammer et al suggested that the deficient activity and migration of cephalic neural crest cells might be related to vitamin A teratogenicity. ${ }^{18}$

DiGeorge syndrome is rarely diagnosed before operation or necropsy. This may be because hypocalcaemia is not often the presenting feature and abnormal susceptibility to infections only becomes obvious in the first months of life in the few patients who have a normal heart or survive with a cardiovascular malformation. Clinical recognition is important if cardiac surgery is considered, because the transfusion of irradiated blood may avoid a serious graft versus host reaction. ${ }^{11}$ The clinician should suspect DiGeorge syndrome in infants with interruption of the aortic arch or truncus arteriosus, particularly if they have facial stigmata and hypocalcaemia. Our study indicates that the degree of suspicion should be even higher if the interruption of the aortic arch is associated with a right-sided descending aorta.

\section{References}

1 Celoria G, Patton R. Congenital absence of the aortic arch. Am Heart J 1959;58:407-13.

2 Van Praagh R, Bernhard WF, Rosenthal A, Parisi LF, Fyler DC. Interrupted aortic arch: surgical treatment. Am J Cardiol 1971;27:200-11.

3 Van Mierop LH, Kutsche LM. Interruption of the aortic arch and coarctation of the aorta: pathogenetic relations. Am J Cardiol 1984;54:829-34.

4 Kleinerman J, Yang WM, Hackel DB, Kaufman N. Absence of the transverse aortic arch. Arch Pathol 1958;65:490-8.
5 Moerman P, Goddeeris P, Lauweryns J, Van der Hauwaert LG. Cardiovascular malformations in DiGeorge syndrome (congenital absence or hypoplasia of the thymus). Br Heart J 1980;44:452-9.

6 Pierpont ME, Zollikofer CL, Moller JH, Edwards JE. Interruption of the aortic arch with right descending aorta. A rare condition and a cause of bronchial compression. Pediatr Cardiol 1982;2:153-9.

7 Lischner H. DiGeorge syndrome(s). J Pediatr 1972;81: $1042-4$.

8 Becker AE, Anderson RH. Pathology of congenital heart disease. London: Butterworths, 1981:93-117.

9 Freedom RM, Rosen FS, Nadas AS. Congenital cardiovascular disease and anomalies of the third and fourth pharyngeal pouch. Circulation 1972; 46:165-72.

10 Conley ME, Beckwith JB, Mancer JF, Tenckhoff L. The spectrum of the DiGeorge syndrome. J Pediatr 1979;94:883-90.

11 Van Mierop LH, Kutsche LM. Cardiovascular anomalies in DiGeorge syndrome and importance of neural crest as a possible pathogenetic factor. Am J Cardiol 1986;58:133-7.

12 Duncan WJ, Tyrrell MJ, Bharadwaj B, Rosenberg AM, Schroeder ML, Bingham WT. Complex transposition with interrupted right aortic arch and partial DiGeorge syndrome. Pediatr Cardiol 1984;5:217-20.

13 Kirby ML, Gale TF, Stewart DE. Neural crest cells contribute to normal aorticopulmonary septation. Science 1983;220:1059-61.

14 Bockman DE, Kirby ML. Dependence of thymus development on derivatives of the neural crest. Science 1984;223:498-500.

15 Clark EB, Hu N, Rosenquist GC. Effect of conotruncal constriction on aortic-mitral valve continuity in the stage 18,21 and 24 chick embryo. Am J Cardiol 1984;53:324-7.

16 Weston JA. The migration on differentiation of neural crest cells. Advances in Morphology 1970;8:41-114.

17 Robinson HB. DiGeorge's or the III-IV pharyngeal pouch syndrome. Pathology and a theory of pathogenesis. Perspect Pediatr Pathol 1975;2:173-206.

18 Lammer EJ, Chen DT, Hoar RM, et al. Retinoic acid embryopathy. $N$ Engl J Med 1985;313:837-41. 